"COMUNICACIÓN INCLUSIVA: UNA EXPERIENCIA EN CREACIÓN DE CAMPAÑAS SOBRE DISCAPACIDAD INTELECTUAL"

AUTORES: Dra. de Andrés del Campo, Susana y Dr. González Martín, Rodrigo. Universidad de Valladolid.

\title{
Comunicación inclusiva: Una experiencia en creación de campañas sobre discapacidad intelectual
}

\section{Inclusive Communication: An Experience in Creation of Campaigns on Intellectual Disability}




\title{
Resumen
}

El presente artículo describe el desarrollo de una práctica didáctica realizada con universitarios que cursan estudios de Publicidad y RR.PP. La primera parte del artículo sitúa la fundamentación académica y el marco propositivo del nuevo Espacio Europeo de Educación Superior en el que se contextualiza y orienta el proyecto. A partir de una deliberación en torno al marco conceptual más adecuado para abordar la relación entre comunicación y discapacidad se adopta la idea de comunicación inclusiva, llegando a una definición aspiracional de la misma. Sobre dicha base conceptual, se expone la metodología didáctica diseñada para propiciar el aprendizaje práctico en la creación de campañas de sensibilización en favor de los derechos de las personas con discapacidad intelectual. El objetivo de la experiencia es avanzar en la innovación creativa de las imágenes y representaciones de las personas con discapacidad intelectual, creando campañas simulacro, a partir de un aprendizaje experiencial y de un proceso inclusivo que tenga en cuenta la participación y evaluación de expertos en comunicación y en discapacidad, así como de las propias personas aludidas. Como resultado de innovación se relacionan los temas, reivindicaciones y representaciones inéditos generados, y se analiza cómo dicho proceso de aprendizaje influye en la composición de un cierto ideario que el alumnado participante ha terminado concibiendo sobre el papel que la comunicación publicitaria puede desempeñar en relación con el problema social sobre la discapacidad intelectual. El artículo termina valorando los procesos de una investigación social basada en la creatividad.

\section{Palabras clave}

Publicidad, discapacidad intelectual, campañas, sensibilización, accesibilidad, inclusividad, integración

\begin{abstract}
This article describes the development of a teaching practice done with students of Advertising and Communication for Social Purposes. The first part of this article places the academic foundation and purposeful framework of the new European Higher Education Area in which the project is contextualized and directed. After a deliberation on the most appropriate framework to address the relationship between communication and disability, the article takes the idea of inclusive communication, reaching an aspirational definition of it. On this conceptual base, we illustrate the teaching methodology designed to promote practical learning in creating campaigns for the rights of people with intellectual disabilities. The aim of the experience is to advance creative innovation of the images and representations of people with intellectual disabilities, creating mock campaigns, from experiential learning and an inclusive process that takes into account the participation and evaluation of communication experts on disability, as well as the persons the ads referred. As a result of innovation we relate unprecedented issues, claims and representations, and discuss how the learning process influences the composition of a certain ideology that the participant students had designed about the role that advertising can play in relation to the social problem of intellectual disability. The article concludes by assessing the processes of social research based on creativity.
\end{abstract}

\section{Key words}

Advertising, Intellectual Disability, campaigns, sensibilization, accessibility, inclusivity, integration 


\section{Introducción}

El presente texto expone algunos aspectos, conceptuales, metodológicos y propositivos, de un proyecto sobre comunicación publicitaria inclusiva con las personas con discapacidad intelectual. El artículo es resultado de una investigación más amplia realizada sobre la innovación creativa de la imagen de las personas con discapacidad intelectual. Una investigación se ha desarrollado en relación con un proyecto de innovación docentel partiendo de la idea de vínculo natural, por razones cognitivas, y necesario, por compromisos sociales, entre la labor docente e investigadora propias del trabajo académico.

El modelo de investigación seguido, se ha planteado desde un concepto amplio de desarrollo personal, como una capacidad constructiva del espíritu y siguiendo la escuela clásica de Jean Piaget, quien explicaba el desarrollo intelectual a partir de la capacidad y competencia simbólica del individuo. La publicidad basa sus procesos creativos en la transformación del mundo de los objetos y los sujetos en signos o símbolos y por tanto el aprendizaje de la creatividad publicitaria puede constituir un entrenamiento en la abstracción y en los procesos lógicos de creación sígnica. También, en línea con el gran concepto de aprendizaje significativo que acuñara Lev Vigotski, y desarrollaran posteriormente Jerome Bruner y David Paul Ausubel, se ha pretendido fomentar el aprendizaje de los procesos de planificación y creación de campañas desde un modelo social de aprendizaje y a través del lenguaje publicitario como instrumento complejo y de aprendizaje por descubrimiento e implicación. En última instancia, se ha pretendido, sin idealismos, proponer un proceso de investigación que se esfuerce más en los fines de la investigación, que en sus métodos, y nos encamine hacia una mayor libertad humana, en sintonía con el pensamiento de Noam Chomsky.

La investigación gira en torno a la idea de discapacidad intelectual en la denominación² y definición actualizada que se consensúa sobre todo a partir del año 1992, momento en que la Asociación Americana sobre Discapacidades Intelectuales y del Desarrollo (AAIDD) alejaba el concepto de retraso mental ${ }^{3}$ como rasgo del individuo "(...) para plantear una concepción basada en la interacción de la persona y el contexto" (Verdugo, 2009:13). El enfoque actual de la discapacidad intelectual es multidimensional:

... dejando atrás sistemas de clasificación que contemplen únicamente como criterio bien la etiología de la discapacidad, bien medidas de inteligencia o conducta adaptativa exclusivamente, para centrarnos en las 5 dimensiones ya

\footnotetext{
1 Grupo de Innovación docente en Metodologías participativas y constructivas en estudios de comunicación. Universidad de Valladolid. Resolución Rectoral de de 12 de noviembre de 2009. Convocatoria de grupos de innovación docente para el espacio europeo de educación superior.

2 Como resumen Verdugo y Schalock (2010:9) los términos utilizados históricamente fueron el de deficiencia mental (1908-1958) y retraso mental (1959-2009) en el ámbito internacional. En España también se han utilizado los términos subnormalidad, que todavía es marginalmente utilizado, y minusvalía mental, que, incomprensiblemente según los autores, ha permanecido hasta muy recientemente. Los últimos avances de la definición han sido publicados en (AAIDD, 2011).

${ }^{3}$ El término "retraso mental" fue eliminado definitivamente en enero de 2007 por el Comité de Terminología y Clasificación de la AAIDD, Asociación Americana de discapacidad intelectual y del desarrollo (Verdugo, 2009:16).
} 
propuestas por la AAIDD en 2002 (funcionamiento intelectual, conducta adaptativa, salud, contexto e interacciones, participación y roles sociales) sin olvidar la necesidad de tener en cuenta el perfil de los apoyos necesarios (Navas, Verdugo y Gómez, 2008: 147).

Desde la definición de 2002 de dicha asociación, se subrayaba la importancia del contexto, entendido como ambientes y cultura, como cuarta dimensión de un problema que antes se interpretaba en términos psicológicos, intelectuales, físicos y de salud, fundamentalmente. Esta investigación se focaliza en dicha cuarta dimensión del contexto, concretamente promoviendo la creación de nuevos signos significados culturalmente. En última instancia, la cultura es el conjunto de símbolos que compartimos y reproducimos. Trabajar en el estatus simbólico de un colectivo, es una importante vía de innovación para superar prejuicios y propiciar su inclusión social.

El proyecto aquí presentado ha pretendido crear un proceso de innovación en imágenes y representaciones, fruto también de la renovación y el cuestionamiento de imágenes mentales y estereotipos, sobre las personas con discapacidad intelectual. A partir de la búsqueda de nuevas palabras y signos visuales para representar la discapacidad intelectual, se generan significaciones y creaciones de sentido diferencial e integrador, lo que fomenta el desarrollo del pensamiento crítico sobre lo que entendemos o sabemos sobre la discapacidad intelectual y propicia una definición ${ }^{4}$ y representación actualizada de la misma.

Esta investigación se basa en estudios anteriores que demuestran cómo las campañas publicitarias pueden ser un catalizador de nuevas imágenes positivas sobre la discapacidad (Shapiro, 1993) así como la importancia de la comunicación en la construcción social de la discapacidad (Rubio, 1999). Sobre este marco de posibilidad, se basa una parte del proyecto dirigido hacia la innovación representacional, animando a jóvenes estudiantes de publicidad, a crear campañas innovadoras que representaran imágenes positivas de las personas con discapacidad. Como definición del marco metodológico y teórico de esta experiencia didáctica, se comentan algunos de los procesos ensayados para propiciar una comunicación publicitaria inclusiva, desde la discusión misma el propio concepto y marcando los objetivos teóricos que la orienten.

\section{Crear una sociedad integradora, como reto universitario.}

El marco general de la investigación ha sido la definición aspiracional de un nuevo modelo de comunicación inclusiva, en el que trabajar desde el ámbito académico de los estudios universitarios de comunicación. El proyecto se ha definido dentro de los fundamentos sociales de la nueva universidad contemplados por el Marco Europeo de Educación Superior (EEES).

Las sucesivas convenciones realizadas en la construcción del Espacio Europeo de Educación Superior enfatizan la dimensión social entre los fines esenciales de la universidad. La Conferencia de Ministros de Praga (mayo 2001) insistía en el reto de contribuir a la cohesión social, la igualdad de oportunidades y la calidad de vida de las personas ${ }^{5}$, aspecto que quedó remarcado en el informe 2006 de la Comisión Europea y el

\footnotetext{
4 "Al definir, sólo se trata, en efecto, de suscitar en otro hombre, nombrando un nombre, las significaciones que yo ya tengo y deseo que él también tenga". Rickert (1960;387)

${ }^{5}$ Towards the European Higher Education Area. Communiqué of the meeting of European Ministers in charge of Higher Education in Prague on May 19th 2001;.2.:

"Lifelong learning is an essential element of the European Higher Education Area. In the future Europe, built upon a knowledge-based society and economy, lifelong learning strategies are necessary to face the challenges of
} 
Consejo de Educación. En el año 2010, la Declaración de Lisboa, en su punto 5 titulado Las universidades y una sociedad integradora se señalaba:

Las universidades europeas aceptan su responsabilidad pública en la promoción de la equidad social y de una sociedad integradora.

En este ideario de lo que supone el llamado proceso de Bolonia, se alude a una formación de calidad que construya no sólo formación profesional sino también ciudadana. Y en esta orientación se ha diseñado una experiencia de innovación docente en la Universidad de Valladolid, dentro de un proyecto de investigación e innovación sobre comunicación, creatividad y discapacidad intelectual ${ }^{6}$.

Propiciado por este marco del proceso de construcción del Espacio Europeo de Educación Superior (EEES) la disciplina de la comunicación, se encuentra replanteando su ubicación tanto epistemológica como académica e incluso profesional ante las demandas cada vez más diversas de la sociedad que vivimos y especialmente en la aludida dimensión social de la comunicación. Los procesos de la comunicación publicitaria, en concreto, se enmarcan cada vez más dentro de parámetros como la ética, el autocontrol y la Responsabilidad Social (Andrés, 2010: 65):

El reto de asumir fines éticos impregna todo el proceso publicitario, todo el proyecto de su sistema. Implica asumir no la etiqueta, sino el compromiso de la responsabilidad social.

Los mensajes son evaluados desde procesos de respuesta propios de una ciudadanía crítica y participativa, y los procesos normativos, tanto regulativos como autorregulativos, cada vez demandan mayores niveles de exigencia ${ }^{7}$ a los medios de comunicación.

Uno de los grandes retos ahora reivindicados a la comunicación está siendo la integración social. Durante el Consejo Europeo de Lisboa de marzo de 2000, se marcó un nuevo objetivo para Europa: convertirse en una economía del conocimiento más competitiva y, a la vez, en una sociedad del conocimiento que propicie la integración social, un aspecto que también atañe a la comunicación. Junto a accesibilidad, inclusividad y alfabetización mediática, se eleva también el compromiso mediático de la integración. El concepto general de integración, desde un punto de vista sociológico, incluye de hecho el papel de la comunicación social. Según Sánchez de Amo (2003: 193):

La integración social es un concepto amplio que alude a varios aspectos: implicación en tareas productivas, participación en tareas sociales informales, desempeño de distintos roles, satisfacción con la calidad de vida... Pero la integración social no pasa exclusivamente por establecer mecanismo, servicios o dispositivos de prevención y rehabilitación, sino que también viene condicionada por

competitiveness and the use of new technologies and to improve social cohesion, equal opportunities and the quality of life".

(http://crue.org/export/sites/Crue/procbolonia/documentos/antecedentes/3._Comunicado_de_Praga.pdf) (29-022011).

\footnotetext{
${ }^{7}$ En el caso de España puede servir de ejemplo el caso de leyes específicas de la comunicación como la Ley 8/2009 de Financiación de la Corporación de Radio y Televisión Española, de 29/2005 de Publicidad y Comunicación Institucional, la Ley 7/2010 General de la Comunicación Audiovisual, la ley 3/1998 de Accesibilidad y Supresión de Barreras Arquitectónicas, Urbanísticas y de la Comunicación.

${ }^{8}$ http://www.europa.europa.eu/summitis/lis1_en.htm (29-02-2011).
} 
la solución de problemas de imagen pública, que frenan o entorpecen acciones de equiparación de oportunidades.

Es relevante el uso del concepto de integración cuando se habla de representaciones y proyecciones de imágenes en la comunicación. En este sentido, el reflejo de la discapacidad como una realidad integrada en las imágenes del llamado mainstreaming de la cultura es aún un terreno por abonar. Como ejemplo revelador, puede mencionarse un estudio realizado sobre las fotografías de la revista Sports Illustrated for Kids, donde fueron muy pocas las imágenes encontradas en las que atletas infantiles con discapacidad fueran representados en equipo (Hardin, 2001:56):

However, it is clear that athletes with disabilities are depicted as segregated and more suited to individual than team sports. These images contradict the goals of integrated education and imply that segregated participation is natural.

Pero integración sería un concepto asimilable a la mera idea de incorporación. Integrar significa meter dentro de otra categoría mayor, por lo que no se basa tanto en el reconocimiento de la diferencia, como en el propósito de incorporar la diferencia dentro de "la norma". Sería necesario superar el mero proceso sumativo, de añadido, que la mera idea de asimilación impone cuando se pretende integrar colectivos minoritarios en otros mayores. La integración adquiere un valor meramente cuantitativo, estadístico, que disimula, cuando no oculta, aquellos rasgos diferenciales y cualitativos de las minorías. El tema es controvertido y ciertas tendencias funcionalistas aún justifican posiciones y discursos políticos, disfrazados de liberalismo, para proponer programas de integración de colectivos basados en las llamadas "cartas de integración", que con frecuencia pretenden la interiorización de valores y creencias normativas. Con frecuencia los proyectos de integración terminan afirmando que la unidad prima sobre la diferencia.

En el ideario cognitivo del proyecto que exponemos, ni la integración ha de ser mera integridad, ni la completitud mera rectitud. Para superar la controversia del concepto de integración, tomaremos en cambio el de inclusión. Una sociedad llamada inclusiva se situaría en un grado superior de cultura cosmopolita y no meramente intercultural 0 multicultural.

\section{Hacia un modelo de comunicación inclusiva.}

El de comunicación inclusiva es uno de los conceptos emergentes que vienen a liderar el mapa axiológico de la nueva comunicación. Un indicador relevante es la estadística de menciones bibliográficas al concepto, tal como puede comprobarse en los resultados de una simple búsqueda con los motores de búsqueda de google labs:

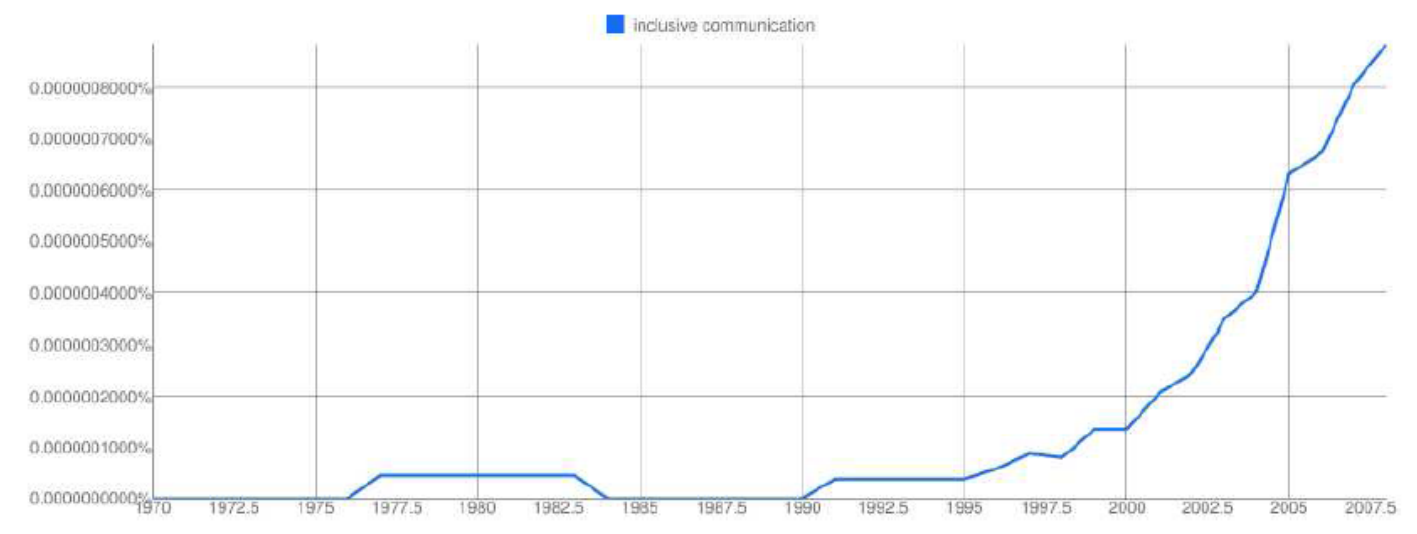


Gráfico de frecuencia de la mención en bibliografía del término Inclusive communication (inglés británico) desde 1970 hasta 2008. Resultados obtenidos con la herramienta Google Books Ngram Viewer, con fecha 12-3-2011.

El concepto anglosajón de comunicación inclusiva, inclusive communication, está además fuertemente asociado a la discapacidad y es probable que constituya uno de los campos que solicite mayores compromisos éticos y deontológicos a medio y largo plazo en el desarrollo de la comunicación. En relación con ello, es creciente la preocupación que las políticas sobre discapacidad muestran, por ejemplo, sobre las limitaciones vocacionales de las personas con discapacidad, al no recibir representaciones o modelos de referencia. De ahí la necesidad de que la discapacidad se relacione con las formas y modos de producción, sobre todo en tanto que ha sido el sistema de producción el que ha provocado cierto grado estadístico de discapacidad y el que a su vez, justificaba su histórica exclusión, tanto laboral y económica como, por ende, social. En palabras de Harm (1987: 551):

Clearly the process of industrialization under capitalism is a mayor factor that has contributed to the prevalence of disability.

La inclusividad de la comunicación es un concepto complejo, que suele relacionarse a priori con dos grandes desarrollos: la alfabetización mediática y la accesibilidad de la información. En primer lugar, la alfabetización mediática es una idea educativa que admite una conceptualización amplia. Podemos tomar la definición siguiente de Siver (2009:19):

...la capacidad de acceso a los medios de comunicación para comprender y evaluar críticamente los contenidos mediáticos y los aspectos diferentes de los medios de comunicación y para crear comunicaciones en una variedad de contextos.

Puede verse que el concepto incluye aspectos relacionados con la emisión, difusión y recepción de la información y se vincula a los medios de comunicación. Es por ello que el contexto de nuevos medios de tecnología digital accesibles a comunidades de niños y jóvenes ha hecho cobrar gran relevancia al concepto de alfabetización digital, acuñado en estudios críticos como los de García Matilla y Molina Caballete (2008:86):

La alfabetización digital en su sentido más amplio debería ser el instrumento que permitiera vertebrar y dar sentido a procesos de diseño, producción y aprovechamiento social, educativo y cultural, que ahora son más exigidos que nunca.

Desde el anterior concepto de alfabetidad de Dondis (1992:10), la alfabetidad significa que todos los miembros de un grupo comparten el significado asignado a un cuerpo común de información. En definitiva, la alfabetización de todo lenguaje sea natural o formal, verbal o audiovisual, inmediato o mediatizado, personal o colectivo, propicia la inclusión, ya que consigue que se compartan competencias de comprensión básicas que posibiliten la plena participación y por ende la democratización desde la comunicación. Por su parte, el concepto de accesibilidad es también uno de los proyectos de acción y desarrollo definidos por la política europea y su aplicabilidad va más allá de los medios de comunicación. La idea de accesibilidad ha sido entendida habitualmente como un problema de soluciones técnicas, cuya innovación ha seguido fundamentalmente criterios 
tecnológicos, que permitan transformar y duplicar la información en códigos adaptados (braille, subtítulos, etc).

La Ley de Accesibilidad de 1998 planteaba los problemas arquitectónicos a la vez que los de comunicación (Ley 3/1998, de 24 de junio de Accesibilidad y Supresión de Barreras Arquitectónicas, Urbanísticas y de la Comunicación). La demanda normativa exigía una accesibilidad tecnológica o de traducción en la comunicación. Pero es evidente que la garantía de la accesibilidad no puede conformarse con el cumplimento de la traducción a códigos adaptados. La traductología no puede garantizar por sí sola una sociedad inclusiva. Los códigos adaptados también segregan, demarcar diferencias, y pueden ser igualmente excluyentes, ya que muchos no son universales. Sin negar con esto la absoluta necesidad de los mismos ni del magnífico potencial de inclusividad que propician, es necesario caminar en más direcciones.

La idea de accesibilidad no sólo se refiere a los medios y su tecnología, sino también a los mensajes y especialmente a la pragmática de sus lenguajes. En palabras de Onghena (2009:11):

Se trata de crear una unidad cultural, no tanto en contenidos, sino en la acogida y el uso que hacen las personas de las creaciones materiales e inmateriales.

Desde el punto de vista del lenguaje y su accesibilidad para las personas con discapacidad intelectual, uno de los principales avances ha sido la llamada lectura fácil?, modelo de adaptación de la información a personas con dificultad para comprender unidades sintácticas complejas o de significaciones complejas, por ejemplo niños, personas escasamente alfabetizadas, personas con vista cansada, personas que no dominan el idioma, etc. En el caso de la publicidad para o sobre personas con discapacidad conviene garantizarse la lecturabilidad de los mensajes por parte de los públicos implicados. Al menos para no defraudar a su vieja reivindicación "Nihil de nobis, sine nobis" (nada sobre nosotros, sin nosotros) ${ }^{10}$. Sería conveniente realizar mensajes divulgativos sobre la discapacidad intelectual propiciando siempre la comprensión de dichos mensajes por estas personas. El compromiso del nuevo comunicador pasaría por crear mensajes no sobre el otro, sino para el otro y con el otro, teniéndole en cuenta; propiciar así que los mensajes sean no sólo legibles y comprensibles, sino apropiables por el grupo afectado.

Tomamos como referencia el Concepto Europeo de Accesibilidad (IMSERSO, 1996) en el que:

La accesibilidad es una característica básica del entorno construido (...). La accesibilidad permite a las personas participar en las actividades sociales y económicas para las que se ha concebido el entorno construido.

Aunque este concepto aludía especialmente al acceso físico a los entornos culturales, se extraía del mismo la conclusión de que la ausencia de accesibilidad actúa como factor discriminante (Fraiz \& otros, 2008: 410):

\footnotetext{
${ }^{9}$ En España, la Asociación Lectura Fácil fue creada en el año 2003. http://www.lecturafacil.net/

${ }^{10}$ Eslogan atribuido a los activistas sudafricanos Michael Masutha y William Rowland, en su lucha por los derechos de las personas con discapacidad en el año 1993. El grito pasó a resumir la filosofía del movimiento por los derechos de los discapacitados (Disability Rights Movement, DRM) y se convirtió en el título del conocido libro de Charlton, J. (1998): Nothing About Us Without Us. Berkeley and Los Angeles: University of California Press
} 
El concepto de accesibilidad involucra una dimensión social y otra técnica. La primera porque implica un derecho de la persona a la no discriminación por ningún tipo de causa justificada, lo que desemboca en una serie de infraestructuras y medios que permitan dicha igualdad de disfrute de derechos fundamentales.

Este concepto de acceso a los medios de comunicación es el único de los aquí discutidos que es mencionado y requerido en la Ley 29/2005, de 29 de Diciembre de Presidencia de Gobierno (BOE. número 312 de 30/12/2005), de Publicidad y Comunicación Institucional, lo que da indicio de su importancia en la política de igualdad, tal como se recoge en su exposición de motivos ${ }^{11}$ :

Por ello se ordena la utilización de medios, soportes o formatos que, por un lado, aseguren el acceso a la información de las personas con discapacidad y, por otro, atendiendo a criterios objetivos, garanticen mejor la difusión de los mensajes (....)

Además, la Ley otorga prioridad a este objetivo ampliando el número de receptores potenciales incorporando previsiones tendentes a garantizar la accesibilidad de las personas con discapacidad y edad avanzada a los contenidos de la publicidad institucional que se realicen y difundan en soporte audiovisual y la pluralidad lingüística de las campañas.

Otras normas legales que mencionan la accesibilidad de la comunicación son la Ley 56/2007, de 28 de Diciembre de Presidencia de Gobierno (BOE número 312 de 29/12/2007), de Medidas de Impulso de la Sociedad de la Información; la Ley 8/2009, de 28 de agosto de Presidencia de Gobierno (BOE número 210 de 29 de agosto), de Financiación de la Corporación de Radio y Televisión Española; la Ley 7/2010, de 31 de marzo de Jefatura del Estado (BOE número 79 de 1 de abril) General de la Comunicación Audiovisual;

Es necesario asumir siempre una perspectiva crítica sobre el momento alcanzado y asumir nuevos compromisos. En este sentido, se trata de construir una comprensión de la comunicación desde su máximos y posibilidades, desde sus fines y no desde sus medios y que contemple toda una serie de ideas finalistas, como la inclusividad.

Cabe también hablar de inclusividad como característica de lo procesos de la comunicación, y no sólo como la final adaptación de los mensajes. La idea de alfabetización y adquisición de competencias para la comprensión de los contenidos de los medios de comunicación no puede conformarse con una alfabetización en los códigos de medios y mensajes. El compromiso de la comunicación accesible sería también crear mensajes con el otro. En este sentido la comunicación accesible sería también inclusiva. Para ello, sería necesario ir introduciendo procesos participativos en las diferentes fases de la producción de los contenidos divulgativos. En el caso de las campañas creadas por estudiantes universitarios en la experiencia que describimos, se propició la participación de personas con discapacidad intelectual en diferentes fases de creación de sus planes de comunicación (investigación, ideación, creación, evaluación).

En concreto la publicidad, tanto por el lenguaje como por los soportes que utiliza, es un entorno de especialización en procesos divulgativos y contenidos dirigidos a un gran público. La fácil comprensión de sus códigos, la rapidez y repetición de sus mensajes facilitan un entorno de grandes posibilidades para ensayar un modelo de comunicación basado en la accesibilidad y la universalidad.

\footnotetext{
${ }^{11}$ Referencias a la accesibilidad y/o a la discapacidad se incluyen también en el Capítulo $\mathrm{V}$ sobre Obligaciones adicionales de servicio público, Artículo 9 e. y 9 o. Una relación más amplia sobre la legislación sobre accesibilidad para la sociedad de la información, puede encontrarse en la Fundación SIDAR para el acceso universal: http://www.sidar.org/recur/direc/legis/espa.php
} 
De esta forma, la inclusividad se convierte en un modelo cultural. Si la cultura es el conjunto de signos que compartimos, las posibilidades de conformación cultural de un modelo inclusivo de comunicación, pasan por la difusión y fácil asimilación de mensajes diseñados en ese fin.

Participando de los objetivos imprescindibles de alfabetización mediática, accesibilidad e integración social, elegimos finalmente la idea de inclusividad, como finalidad de la comunicación. En conclusión, un modelo de comunicación inclusiva fomentaría la capacidad de expresión, comprensión y participación de todos los sujetos y públicos que interactúan en un proceso de comunicación, así como la garantía de unas mínimas condiciones de igualdad entre los mismos, propiciando su accesibilidad de medios y mensajes y su integración simbólica en los contenidos y representaciones.

Entendemos por comunicación inclusiva la conformación y potenciación de un entorno de información y de conocimiento abierto, creativo, participativo y responsable, en el que intervengan de forma activa, según sus diversas capacidades, todos los sujetos que, como ciudadanos plenos, se comprometen en construir una sociedad y una cultura dialogante y tolerante en condiciones básicas de igualdad y justicia. La comunicación inclusiva sería un escenario de oportunidades polivalentes, en el que se garantizaran libre y creativamente las más amplias posibilidades de accesibilidad y generación de mensajes y en el que se representaran los fines de dignidad de todas las personas, con riqueza simbólica, dando visibilidad a las diferentes identidades de los colectivos sociales, sean minoritarios o mayoritarios.

\section{Metodología didáctica}

La experiencia que desencadena el objeto de este artículo se viene desarrollando desde el año 2005 en la licenciatura de Publicidad y RR.PP., y desde 2008 en el Master Oficial Europeo en Comunicación con Fines Sociales, Estrategias y Campañas. Ambas titulaciones son impartidas en el Campus de Segovia de la Universidad de Valladolid.

Dentro del contexto del programa de docencia- aprendizaje, el alumnado ha sido invitado a realizar un trabajo voluntario para la adquisición de competencias básicas consistente en diseñar un plan de comunicación así como soluciones creativas adaptadas a un briefing o encargo de campaña. El briefing, cambiante cada curso, es aportado por FEAPS CyL, que funciona como entidad anunciante en la simulación de ejercicio profesional, y que propone la realización de una campaña de sensibilización a favor de las personas con discapacidad intelectual. E alumnado se organiza en grupos de trabajo como si fueran agencias de comunicación. Comienzan a trabajar con un alto grado de realidad, sobre demandas sociales, y mapas reales de públicos y medios. No obstante, se trabaja en un modo simulacro evitando siempre la competencia desleal a empresas de comunicación.

El trabajo tiene un seguimiento académico, con tutorías del profesorado, y un seguimiento profesional, con sucesivos contactos con "el cliente". Finalmente se evalúa académicamente, pero se expone ante representantes de la institución demandante y se somete a una evaluación profesional por parte de su directora de comunicación, Eva Martín de Pedro ${ }^{12}$.

Para promover un modelo de aprendizaje participativo y cooperativo, que oriente también un proceso de desarrollo comunicativo con las mismas características, se programan viajes académicos y actividades de convivencia entre personas con discapacidad intelectual y el alumnado. También desde ambas instituciones (FEAPS CyL y Universidad de Valladolid) se promueven experiencias programadas por los propios grupos

\footnotetext{
${ }^{12}$ Miembro de DIR-COM, Asociación de Directivos de Comunicación. Castilla y León. España.
} 
de alumnos con el objetivo de entrevistar, convivir, realizar rodajes y reportajes fotográficos, documentarse, etc. para la mejor realización de los trabajos de planificación y creatividad sobre la discapacidad intelectual.

El proceso de evaluación de las campañas, a partir de la defensa de las mismas, se realiza desde una metodología participativa, crítica y dialógica, integrando a los diferentes públicos implicados en el proyecto. Durante las semanas finales del curso se celebran 10 sesiones de metodología deliberativa para la evaluación de los planes de comunicación diseñados y de las propuestas creativas ideadas. En estas sesiones participan los públicos implicados y se abre un turno de evaluación dialogada en el que participan:

- Estudiantes universitarios de licenciatura/ máster.

- Directora de Comunicación de FEAPSCyL.

- Presidente y técnicos de la Asociación local de Personas con discapacidad, APADEFIM.

- Personas con discapacidad intelectual.

- Técnicos especializados en los temas de las campañas.

- Directora de Calidad de FEAPSCyL

- Profesorado

Cada año se planifican y diseñan en este proyecto unas 32 campañas a favor de las personas con discapacidad intelectual ${ }^{13}$. Se trata de campañas de sensibilización, a favor de derechos como el ocio inclusivo, un deporte para todos, la integración en la escuela, la atención a personas con discapacidad intelectual en entornos rurales, la promoción de lectura fácil de los medios de comunicación, etc.

Gracias a la colaboración de FEAPS CyL, muchas piezas salidas de estas campañas han sido exhibidas en diferentes exposiciones públicas, realizadas como acción de sensibilización social hacia la discapacidad intelectual. La última exposición ha sido expuesta en la sala Caja de Burgos de la ciudad de Palencia con el nombre "Responsabilidad Social Creativa. Por la inclusión social". De esta forma, las campañas consiguen un efecto real en la sociedad, poniendo a prueba su potencial y validez, tanto para testar la comprensión y el valor de la autoimagen que propician para las personas con discapacidad intelectual, como para comprobar la capacidad de sensibilización en el público en general. Las exposiciones se programan con un plan paralelo de visitas para diferentes públicos y consiguen captar la atención de los medios de comunicación, amplificando dichos objetivos de sensibilización ${ }^{14}$.

\section{De la innovación en la imagen de las personas con discapacidad a la adquisición de nuevas convicciones sobre el papel de la comunicación publicitaria.}

Los objetivos académicos marcados logran cambios tanto aptitudinales como actitudinales. En cuanto a las competencias profesionales, vienen a demostrar las capacidades del alumnado para planificar y crear comunicación con fines sociales. En términos de resultados académicos, la superación de este trabajo da garantía de cierta solvencia del alumnado en la realización de planes de comunicación así como de ideación y realización de creatividad desde la responsabilidad social.

\footnotetext{
${ }^{13}$ Algunas de estas campañas pueden verse en el catálogo Andrés, S.de; González, R. \& otros (2009).

${ }^{14}$ Véase por ejemplo: http://www.abc.es/agencias/noticia.asp?noticia $=590598$

http://www.nortecastilla.es/20101115/local/palencia/alumnos-publicidad-campus-segovia-201011151620.html
} 
Pero este proyecto docente se ha definido dentro de finalidades educativas. En este sentido, se ha trabajado dentro de un modelo de investigación social con grupos de personas, en lo que en metodologías proactivas y participativas se denomina investigación-acción, desde el conocido texto de Kurt Lewin (1946). Y son precisamente las acciones y actividades vinculadas a la investigación las que permiten generar transferencia social.

En el ámbito de las ciencias de la comunicación, la idea de transferencia puede comprometerse con algunos de los fines clave de la investigación universitaria, recogidos en el art. 41.1. de la LOU: "La universidad desarrollará una investigación de calidad y una gestión eficaz de la transferencia de conocimiento y la tecnología, con los objetivos de contribuir al avance del conocimiento y del desarrollo tecnológico, la innovación y la competitividad de las empresas, la mejora de calidad de la vida de la ciudadanía, el progreso económico y social y un desarrollo responsable equitativo y sostenible, así como garantizar el fomento y la consecución de la igualdad".

De acuerdo con ello, esta investigación quería medir sus resultados en términos de innovación en la imagen y representaciones de las personas con discapacidad intelectual, para garantizar también una igualdad en su estatus simbólico. En este sentido, el proyecto ha tenido como resultado la promoción de temas inéditos, como la primera campaña española sobre ocio inclusivo (difundida después por FEAPSCyL y presentada públicamente el día internacional de la discapacidad en 2010) o en la ideación de las primeras campañas promocionando la lectura fácil, reivindicando los derechos de las personas con discapacidad intelectual que habitan en el medio rural, o dignificando al colectivo. Se han logrado imágenes que presentaran a las personas con discapacidad intelectual en contextos a los que escasamente se les asocia, como conciertos de música rock, bares o bibliotecas.

Pero también se mide el cambio de actitudes hacia la discapacidad intelectual provocado en los alumnos que participaran en la experiencia. Para realizar esta medición se diseñó un cuestionario ${ }^{15}$ de preguntas de respuesta cerrada aplicado a una muestra aleatoria de estudiantes participantes en el último año de la experiencia. El perfil de la muestra fue de estudiantes entre 21 y 25 años, El cuestionario fue aplicado a 36 estudiantes que voluntariamente participaron en el proceso de consulta, con un perfil de edad entre 21 y 25 años, procedentes de 15 provincias diferentes. La muestra estuvo constituida por un $56 \%$ de mujeres estudiantes en los estudios superiores antes aludidos.

El cuestionario intentaba indagar en el componente actitudinal de estos futuros profesionales de la comunicación, en dos áreas principales del proceso de la publicidad: la planificación y la creatividad. Entre los resultados mesurados destaca la convicción de los alumnos sobre la idea del papel comprometido y responsable que ha de asumir la creatividad publicitaria versada sobre discapacidad:

\footnotetext{
${ }^{15}$ El formulario y los resultados cuantitativos han sido procesados con la herramienta hoja de cálculo de Google Docs, encuestas on line. Septiembre 2010. El cuestionario fue supervisado por la dirección de calidad de FEAPSCyL.
} 


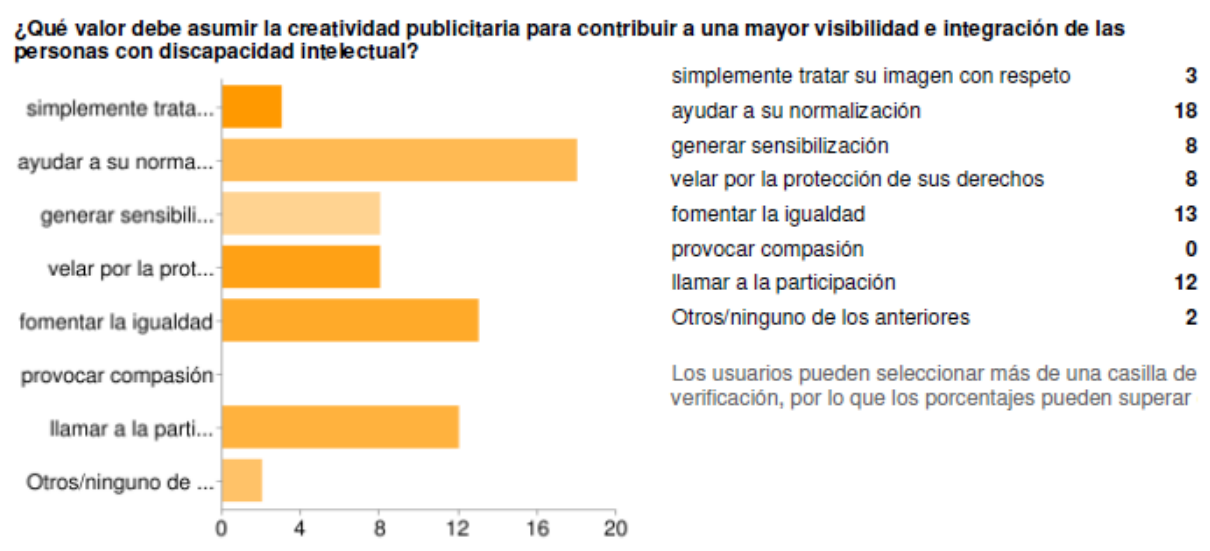

Respuestas obtenidas sobre el valor que debe asumir la creatividad publicitaria con la visibilidad e integración en los mensajes de personas con discapacidad intelectual.

Por otra parte, se preguntó al alumnado sobre los objetivos que han de definir la planificación, indagando en el componente actitudinal del compromiso y función que puede adquirir una campaña con fines sociales. En este aspecto, destacaba el alejamiento del papel que la publicidad debe cumplir al pretender objetivos meramente pecuniarios. La discapacidad intelectual, al fin y al cambo, no necesita solicitar fondos tanto como adquirir empoderamiento simbólico. Dar visibilidad, y sobre todo romper estereotipos, son los objetivos que los alumnos encuestados sitúan como prioritarios.

\section{Si hicieras una campaña sobre la discapacidad intelectual ¿Qué objetivo te parecería más conveniente?}

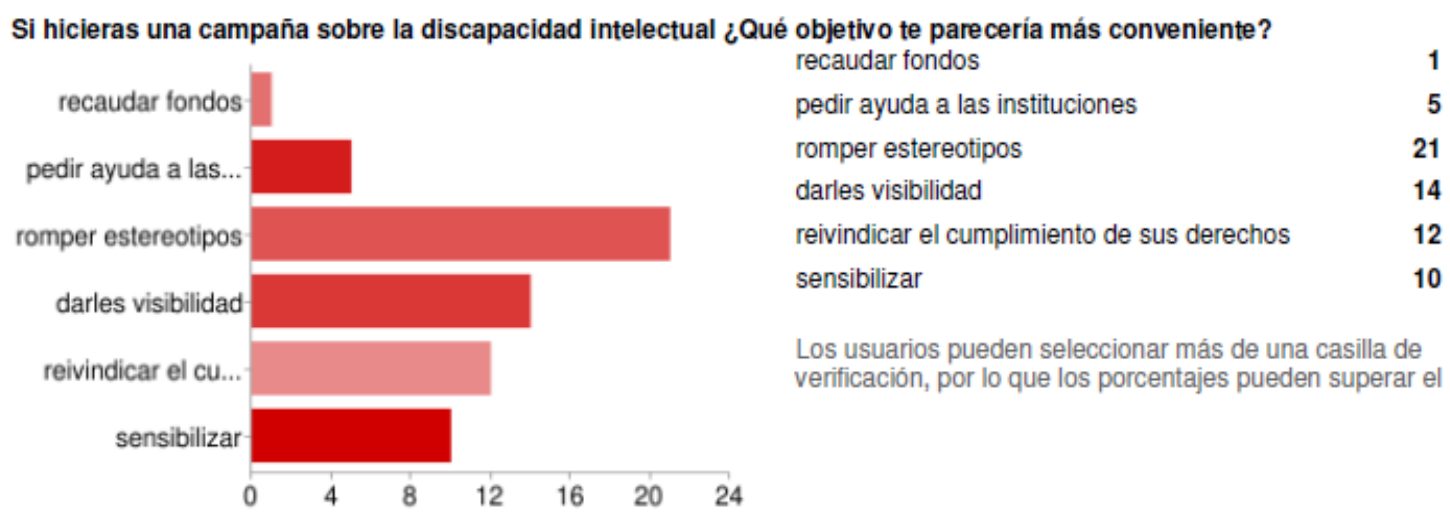

\section{Respuestas obtenidas sobre los objetivos que definiría el alumnado en campañas realizadas en favor de las personas con discapacidad intelectual.}

Estas respuestas, a las que el alumnado llega después de un proceso de inmersión académica, semi-profesional y personal en el mundo de la discapacidad intelectual podemos decir que denota una madurez destacable en el concepto de solidaridad que viene reivindicando la discapacidad intelectual en diferentes declaraciones y documentos marco tanto a nivel internacional como regional, como es la Convención de la ONU de los Derechos de las personas con discapacidad (Naciones Unidas, 2006:9), sus principios, definiciones y convenios, en especial el Art. 8 sobre la "Toma de conciencia" en el que se alude a la lucha contra los estereotipos. 


\section{Investigar para el cambio social.}

La investigación ha de cumplir objetivos de transferencia también en términos sociales. Ha de transferir valores y propiciar el desarrollo cultural, social y la expansión de una serie de valores cívicos y humanos, tal como se define en las nuevas tendencias del sistema universitario europeo y se recoge en documentos como el aportado por la Fundación CyD (2009).

En este sentido, la creatividad pude constituir tanto el proceso como el objetivo para propiciar el desarrollo artístico, definido como uno de los aspectos esenciales de la universidad y la investigación, en el artículo 39 de la LOU.

La dinámica de la práctica docente expuesta en este artículo es un proyecto encaminado a la capacitación profesional en nuevos perfiles de la comunicación, como es la especialización en comunicación con fines sociales, la publicidad sociall' y la comunicación del tercer sector. En este momento de crisis económica y social, la caída de la inversión en medios de comunicación es alarmante, pero destaca que la depresión económica no afecta tanto a la inversión en campañas del tercer sector ${ }^{17}$, un campo que no estaba desarrollado en los viejos planes de estudio de los títulos de las ciencias de la comunicación y al que el proceso de Bolonia tendrá que propiciar y desarrollar. En este momento, no existe un desarrollo académico maduro sobre modelos de planificación de medios y desarrollos estratégicos de campañas adecuados a esta especialización, por lo que hemos de aceptar el grado de incertidumbre y coste de originalidad que trabajar en este campo de la comunicación social aún conlleva.

Pero por encima de perfiles y prácticas pedagógicas, es importante que se defina la labor cotidiana de la docencia e investigación universitarias dentro del marco que subrayábamos en el primer epígrafe de fundamentación. Promover, de manera general, una interacción progresiva y enriquecedora de la Universidad con el entorno social, dando crédito social a la imagen y el papel de la Universidad como institución de reversión solidaria y ciudadana a la inversión compleja que la sociedad hace en esta institución, dando a la producción del conocimiento en el ámbito de la comunicación un valor solidario y una legitimación tanto epistémica como ética y social.

Desde la lógica proposicional a la ética social, la exclusión es el contravalor a superar con la inclusión. Y la inclusión sería una condición para construir democráticamente una comunicación propia de una cultura transversal, comprensiva, donde la diversidad también garantice la creatividad en muchas y diversas estéticas.

\footnotetext{
${ }^{16}$ Concepto que se refiere a "...publicidad generalmente promovida por anunciantes sin ánimo de lucro que deriva de una causa o proyecto social y se dirige al receptor-consumidor típico de las sociedades occidentales desarrolladas. Su finalidad prioritaria es servir a esa causa o proyecto social, en beneficio del bienestar individual o colectivo, ya sea de los receptores y de la sociedad en que éstos viven o de individuos y sociedades lejanas" (Alvarado, M.C. \& Andrés, S de., 2005: 68)

${ }^{17}$ Datos Infoadex. Anuncios (2010:45). Infoadex ha contabilizado para las entidades sin ánimo de lucro una inversión en España de 63,3 millones de euros en 2009. Esta cantidad representaba un crecimiento de casi un 3\% sobre el año anterior. Infoadex calcula la inversión sobre espacios difundidos y cabe aclarar que muchas de estas campañas se difunden con la colaboración de los medios de comunicación en espacios cedidos.
} 
De todas las facetas de este proceso investigador que hemos definido como abierto e inclusivo, los aspectos más significativos, más allá de sus resultados objetivos, quizá sean sus propios procesos, donde se dirime el valor cualitativo de toda investigación social. El gran reto de este proceso ha sido conseguir una alta implicación de públicos en un proceso dialógico y fluido con participación de profesionales, instituciones, estudiantes universitarios, personas con discapacidad, profesorado e investigadores. Al fin y al cabo, todo reto de investigación social podría medirse también en la capacidad para propiciar actividades y procesos dialógicos.

En concreto, el proyecto está aportando evidencias para demostrar que el trabajo creativo de búsqueda de soluciones comunicativas a problemas sociales, desarrollado dentro de una metodología y propuesta de comunicación responsable, propicia un cambio actitudinal positivo así como un aumento de conocimiento sobre el problema tratado. Reforzar y mejorar los procesos de evaluación y medición de resultados será el propósito en la continuación del proyecto. Pero, herramientas metodológicas aparte, cabe continuar siempre en el esfuerzo y compromiso docentes de propiciar una experiencia de transformación personal en valores y creencias normativas sobre el papel de la comunicación y su compromiso con fines sociales.

\section{Apoyos.}

Este proyecto recibió el Premio de Investigación en Responsabilidad Social de la Universidad de Valladolid en 2009 y actualmente se desarrolla con financiación conseguida en convocatoria pública de proyectos de la Junta de Castilla y León. Proyecto de investigación "Innovación en la imagen y comunicación de la discapacidad intelectual. Proyecto de acciones integradas sobre creatividad responsable y análisis de su eficacia en el cambio de conocimiento y actitudes hacia las personas con discapacidad intelectual". Convocatoria 2010 de proyectos de investigación. Código Ref. VA002B10-1. Proyecto elaborado en colaboración y con el apoyo de FEAPS Castilla y León. Federación de entidades, asociaciones y fundaciones de personas con discapacidad intelectual y sus familias, de Castilla y León. España. 


\section{BIBLIOGRAFÍA}

ALVARADO, M.C.; ANDRÉS, S. DE, \& GONZÁLEZ MARTíN, R. (2007). "Discapacidad: estigma y concienciación", Comunicación e cidadanía. Revista Internacional de Xornalismo Social, 1; pp. 203-222.

ALVARADO, M.C. \& ANDRÉS, S. DE (2005). "Una reflexión crítica sobre la publicidad estatal. El Estado żanunciante social?", Telos: Cuadernos de comunicación e innovación, 64; pp. 67-73.

ASOCIACIÓN AMERICANA DE DISCAPACIDADES INTELECTUALES Y DEL DESARROLLO (AAIDD) (2011). Discapacidad Intelectual. Definición, clasificación y sistemas de Apoyo. Undécima Edición. American Association on Intellectual and Developmental Disabilities. Madrid: Alianza Editorial, 2011.

ANDRÉS, S. DE; GONZÁLEZ, R. \& OTROS. (2009). Responsabilidad Social Creativa. Valladolid: Muva, Universidad de Valladolid.

ANDRÉS, S. DE (2010). Tercer tiempo para la publicidad. De las funciones a los fines de un metafenómemo. En Andrés, S. de (coord.). Otros fines de la publicidad. Sevilla-Zamora: Comunicación Social; pp. 47-73.

ANUNCIOS (2010). "Corporaciones y asociaciones: magnitudes estables", Revista Anuncios. Número Extraordinario anual, 153, diciembre de 2010. Ranking de Anunciantes.; p. 45.

CONSEJO EUROPEO DE LISBOA (2000). Conclusiones de la Presidencia I: Empleo, reforma económica y cohesión social. Un objetivo estratégico para la próxima década. Un nuevo reto.

(http://www.europarl.europa.eu/summits/lis1_es.htm) (29-02-2011).

CONSEJO EUROPEO DE PRIMAVERA (2006). Modernizar la educación y la formación: una contribución esencial a la prosperidad y a la cohesión social en Europa. Informe General sobre la actividad de la Unión Europea. Cap II. Enseñanza, educación, aprendizaje. 24 de febrero.

(http://europa.eu/generalreport/es/2006/rg35.htm) (29-02-2011).

CONVENCIÓN EUROPEA DE MINISTROS DE EDUCACIÓN SUPERIOR (2001) Declaración de Praga. Hacia el Área de la Educación Superior Europea. Declaración del encuentro de los Ministros Europeos en funciones de la Educación Superior en Praga. 19 de mayo.

(http://www.ond.vlaanderen.be/hogeronderwijs/bologna/links/language/2001_Prague_C ommunique_Spanish.pdf) (29-02-2011).

DONDIS, D.A. (1992). La sintaxis de la imagen. Introducción al alfabeto visual. Barcelona, Gustavo Gili. 
EUROPEAN UNIVERSITY ASSOCIATION (2010): La Declaración de Lisboa. Las universidades de Europa más allá de 2010: diversidad con un propósito común. Bruselas: EUA.

(http://www.eua.be/fileadmin/user_upload/files/Publications/Lisbon_declaration_final_Spa nish_version.pdf)

(29-02-2011).

FRAIZ BREA, J.A.; ALÉN GONZÁLEZ, M.E., \& DOMÍNGUEZ VILA, T.(2008): La accesibilidad como nexo de unión entre la universidad y la sociedad: la creación de mercados globales e integradores. En Castro Silva, E.J. de (coord.): Universidad, sociedad y mercados globales. International Conference. Madrid: Asociación Española de Dirección y Economía de la Empresa, pp. 409-420.

FUNDACIÓN CYD (2009). Resumen ejecutivo Informe CyD 2009. La contribución de las universidades españolas al desarrollo. Barcelona, Fundación CYD.

GARCÍA MATILLA, A; MOLINA CABALLETE, J.P. (2008). "Televisión y jóvenes en España", Comunicar, 31, XVI, pp. 83-90.

HARDIN, B., HARDIN, M.\& LYNN, S. (2001). "Missing in action? Images of disability in Sports Illustrated for Kids", Disability Studies Quarterly, DSQ, 21-2; pp. 47-59.

HARM, H. (1987). "Advertising the acceptably employable image. Disability and capitalism", Policy Studies Journal, 15-3:551-570.

IMSERSO (1996). Concepto europeo de accesibilidad. CCPT/Marzo 1996. Madrid: CEAPAT. Ministerio de Trabajo y Asuntos Sociales.

LEWIN, KURT (1946). "Action Research and Minority Problems", Journal of Social Issues, 2, IV; pp. 34-46.

Ley 6/2001, de 21 de diciembre, de Universidades. Modificada en BOE n 89, 13-4-2007;

$16241-16260$.

Ley $51 / 2003$, de 2 de diciembre de 2003, de igualdad de oportunidades, no discriminación y accesibilidad de las personas con discapacidad (LIONDAU). BOE n²89, 3-12-2003; pp. 43187-43195.

Ley 29/2005, de 29 de diciembre, de Publicidad y Comunicación Institucional. BOE N³12, 30-12-2005; pp. 42902-42905

MINISTERIO DE TRABAJO Y ASUNTOS SOCIALES (2003). I Plan Nacional de Accesibilidad 2004-2012. Por un nuevo paradigma, el Diseño para Todos, hacia la plena igualdad de oportunidades.

NACIONES UNIDAS (1993). Igualdad de oportunidades para las personas con discapacidad. Resolución 48/96 de 20 de diciembre de Naciones Unidas.

NACIONES UNIDAS (2006). Convención Internacional sobre los derechos de las personas con discapacidad. 13 de diciembre de 2006.

(www.un.org/esa/socdev/enable/documents/tccconvs.pdf) (29-2-2011). 
NAVAS, P.; VERDUGO, M.A. y GÓMEZ, L.E. (2008). "Diagnóstico y clasificación en discapacidad intelectual", Intervención Psicosocial. vol 17, n.2., pp.143-153.

ONGHENA, Y. (2009) (coord.). "Acción cultural inclusiva para un proyecto cultural compartido", Revista CIDOB d'Afers Internacionals, núm. 88, diciembre de 2009, especial Comunicación, espacio público y dinámicas interculturales. Barcelona, pp.9-12.

RICKERT, H. (1960). Teoría de la definición. México: Centro de Estudios Filosóficos. Universidad Autónoma de México.

RUBIO, F.J. (1999) "Estrategias de imagen y comunicación en la construcción social de la discapacidad", Revista de Investigación y Marketing, 64; pp. 6-9.

SÁNCHEZ DE AMO, A. (2003). "Los medios de comunicación ante la discapacidad", Acciones e investigaciones sociales, 17, pp. 183-214.

SHAPIRO, J. (1993). No Pity: People with Disabilities Forging a New Civil Rights Movement. New York: Times Books.

SILVER, A. (2009). "Aproximación europea a la educación en medios: avanzando hacia una sociedad del conocimiento inclusiva". Prólogo. Comunicar, 32, XVl; pp. 19-20.

SIPERSTEIN, G.N. (2003). Estudio multinacional de actitudes hacia las personas con discapacidad intelectual. Center for Social Development and Education. University of Massachussets, Boston. Washington: Comité Olímpico Internacional.

VERDUGO, M.A. \& GUTIÉRREZ, B. (2009). Discapacidad intelectual. Adaptación social y problemas de comportamiento. Madrid: Pirámide.

VERDUGO, M.A. \& SCHALOCK, R.L. (2010). „Últimos avances en el enfoque y concepción de las personas con discapacidad intelectual". Revista Española sobre Discapacidad Intelectual. Vol4 (4), Núm 236; pp. 7-21. 